\title{
PV/Wind Hybrid Energy System, Modeling and Simulation at variable weather conditions
}

\author{
Abdelhamid Slama ${ }^{1}$, Messaoud Hamouda ${ }^{2}$, Mounir Khiat ${ }^{3}$ \\ 1,3 SCAMRE Laboratory, Electrical engineering department, ENPO-MA, Oran, Algeria \\ 2 DDI Laboratory, Ahmed Draia University, 01000, Adrar, Algeria
}

\begin{tabular}{l}
\hline \hline Article Info \\
\hline Article historys: \\
Received Sep 28, 2020 \\
Revised Nov 25, 2020 \\
Accepted Dec 8, 2020
\end{tabular}

\author{
Keywords: \\ PV array; \\ DFIG; \\ THD; \\ grid side converter; \\ DC/DC converter; \\ wind power
}

\begin{abstract}
This paper presents a modeling and simulation of a grid-connected wind / PV hybrid power system under variable weather conditions. This system includes a wind turbine system, a PV system that shares a DC bus, and no battery. The paper contains an overview of the hybrid system and some previous studies; it presents a brief overview of each component used for this system. Signal distortion remains the great obstacle when connecting to the grid, so the system architecture and its proposed control are also introduced to reduce the distortion of electrical signals to an acceptable value. A simulation of the system's operation with specific weather conditions in three different modes was performed using the MATLAB Simulink to describe the effect of these weather conditions on the production of electrical energy. Simulation results show how these weather conditions affect the operation of this hybrid system. An acceptable distortion value of the produced current signals has also been reached. These results present an evaluation of the dynamic performance of this system under the proposed working conditions. It also shows the energy exchange with the grid.
\end{abstract}

Copyright $(2020$ Institute of Advanced Engineering and Science. All rights reserved.

\section{Corresponding Author:}

Abdelhamid Slama,

SCAMRE Laboratory,

Electrical engineering department, ENPO-MA,

Es-Sénia Road, B.P. 1523 El M’Naouer 31000, Oran, Algeria.

Email: abdelhamid.slama@enp-oran.dz

\section{INTRODUCTION}

The electric power production has increased significantly in recent years, due to the great need of energy in all countries and in various fields. Due to high fuel prices and environmental pollution, these led to the production of electric power in systems that operate on renewable natural sources. Thus, single-source and multiple-source systems were used, depending on the weather conditions in the country. Many research papers dealt with different forms of hybrid systems, we review the following: In Hussain Bellamily's paper [1], an alternative approach is proposed using Fuzzy Logic controllers optimized to control the PV-Wind system. This method is based on the use of advanced control strategies for DC-DC and AC-DC regulators in the PV-wind standalone system.

In the paper [2], various energy management strategies for a residential wind photovoltaic hybrid system using lithium-ion storage battery power are studied. Simple and robust performance models for small wind turbines and solar PV panels have also been developed. In the research paper [3], an experimental smart microgrid platform is built with wind / PV / battery power, this platform adopts master, slave and hierarchical control strategy. The power management system designed based on the SOC level of the battery. Intended to optimize the operation mode of the smart small grid system, regulate the state of energy storage, and improve the power balance in the distribution network, generators and distributed loads. In Research [4], Peng Kong worked on proposing a parallel series of high frequency resonant transformers for the autonomous Hybrid Photovoltaic (PV) / wind power system in order to simplify the power system and reduce the cost. Through 
Work [5], a technical and economical simulation school was introduced to design a grid-connected PV system as specifically applied to residential units in Surabaya, Indonesia. In research [6], a study was conducted in a school connected to the grid, and a solar hybrid system and wind were used as backup power during power outages. As this study investigated the dynamics of operation of such a system. The main objective of the study was to understand the operation of the inverter charger in a backup power system. During the study, power generation and load consumption were recorded and the performance of the hybrid system was analyzed. Paper [7] gives the architecture of a hybrid system consisting of solar PV and DFIG based wind turbines that share an alternative line (grid).

In this study, we will study and simulate a hybrid system connected to the grid shared in DC bus, operating according to changing weather conditions in order to study the effect of these conditions on the functioning of the system and an attempt to reduce the THD of electrical signals to the lowest possible value. For that reason, simulations were carried out in three different modes to clarify the effect of each atmospheric factor on the work of this hybrid system.

\section{CONFIGURATION OF THE HYBRID PV/WIND TURBINE SYSTEM}

Figure 1 shows the configuration of the studied hybrid system. This hybrid system contains a solar array, a boost converter, MPPT tracker, an inverter, turbine, DFIG and grid. The boost converter raises the PV voltage to the bus voltage value. The MPPT is implemented to track the maximum power point and produce as much power as possible. The inverter is controlled to regulate the output voltage of the boost converter and generate a power and currents injected to the grid. The turbine captures wind power and transmits it through the shaft to the DFIG that generates electrical power with the chosen control method.

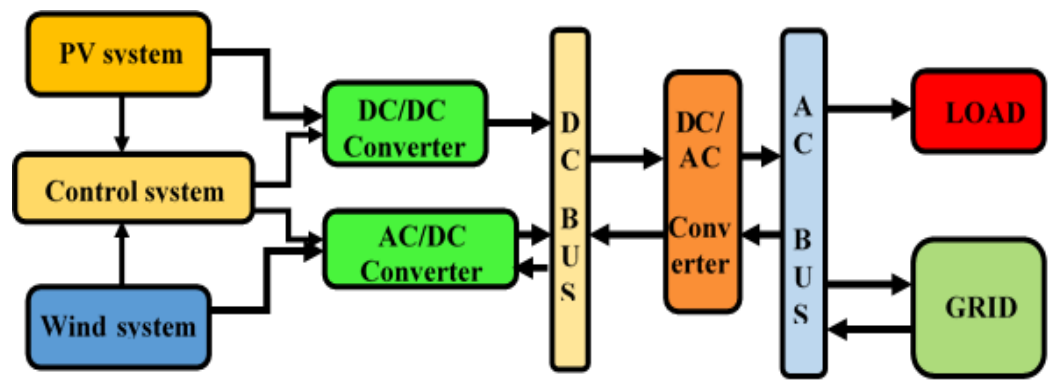

Figure 1. Bloc diagram of PV/Wind turbine hybrid system

\section{PV GENERATION SYSTEM}

\subsection{PV Array}

PV cell is the primary ingredient in PV system. It converts radiation into a voltage and current by the photoelectric effect. Single-diode model of PV cell consists of a photocurrent source, a nonlinear diode, series resistance and shunt resistance. PV cells are arranged together in series and parallel to form arrays [8]. The equivalent circuit of PV array can be described as illustrated in Figure 2.

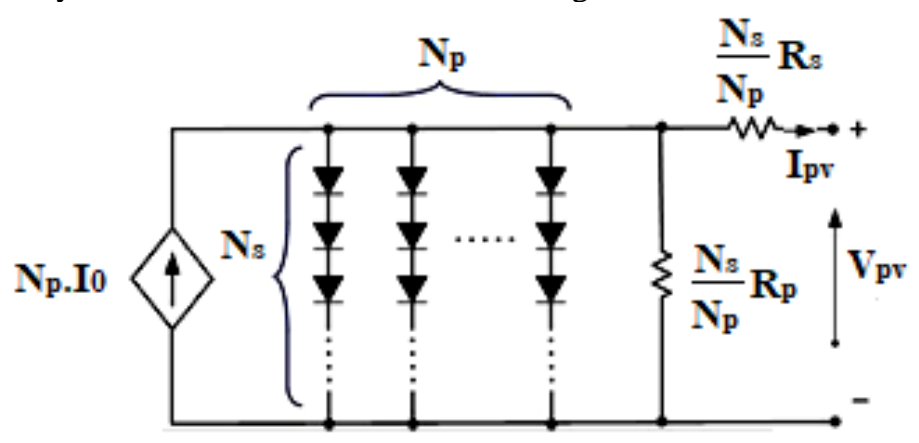

Figure 2. Equivalent circuit of a solar array.

The PV array can be modelled by Equation (1) [9][10].

$$
I_{p v}=N_{p} * I_{0}-N_{p} * I_{c c} *\left[e^{\frac{q}{A . k . T}\left(\frac{V_{p v}}{N_{s}}+\frac{I_{p v} * R_{s}}{N_{p}}\right)}-1\right]-\frac{N_{p}}{R_{p}} *\left(\frac{V_{p v}}{N_{s}}+\frac{I_{p v} * R_{s}}{N_{p}}\right)
$$


Where $\mathrm{I}_{\mathrm{pv}}, \mathrm{V}_{\mathrm{pv}}$ : PV array output current and voltage, $\mathrm{I}_{\mathrm{cc}}$ : Solar cell reverses saturation current, $\mathrm{I}_{0}$ : Solar cell photocurrent, $\mathrm{R}_{\mathrm{S}}$ : Cell intrinsic series resistance, $\mathrm{R}_{\mathrm{P}}$ : Cell intrinsic shunt or parallel resistance, $\mathrm{N}_{\mathrm{S}}$, $\mathrm{N}_{\mathrm{P}}$ : Number of series and parallel connected pv cells

The output power from the PV array is given by equation (2) [11]:

$$
P_{p v}=V_{p v} * I_{p v} * \eta_{c o n v}
$$

Where $\eta_{\text {conv }}$ is the efficiency of the DC-DC converter (typically 90-95\%).

We used the model Canadian Solar CS5P-230M to simulate the operating system in Matlab/Simulink. The parameters of the model are given in Table 1.

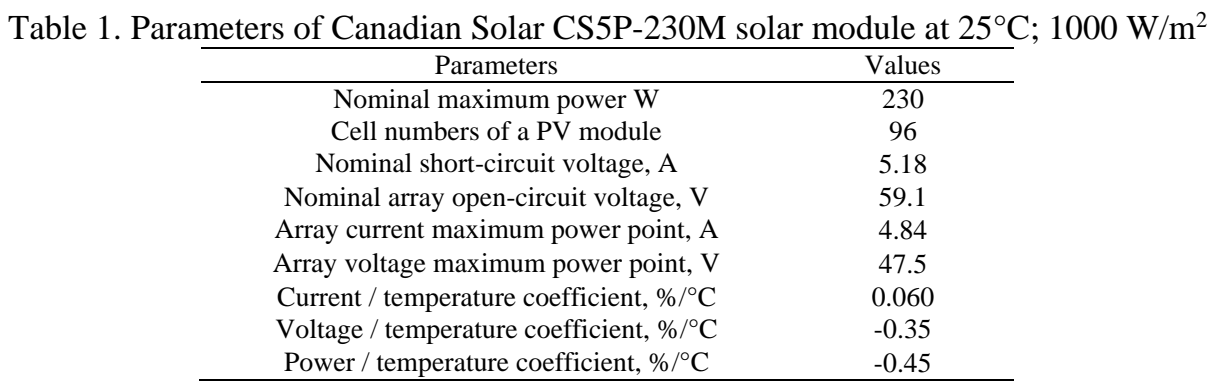

\subsection{DC-DC Converter}

The DC-DC converters are units operated by periodically opening and closing a switch. One of them is the boost converter; it increases the input voltage and converts an unregulated low source voltage to a higher regulated output voltage [9], According to the subsequent relationship (3):

$$
V_{s}=\frac{V_{e}}{1-D}
$$

Where: $\mathrm{D}$ is a duty cycle.

\subsection{MPPT Control}

To utilize the maximum power produced by the solar cell at all times, the regulation system has to be equipped with a maximum power point tracker (MPPT). This is a device, which tracks the voltage at where the maximum power is utilized at all times. Voltage and current sensor are used to sense the PV module voltage and current; this sensed voltage and current are used in the algorithm to search maximum power point. Several algorithms have been developed for this purpose $[12,13]$. The $\mathrm{P} \& \mathrm{O}$ algorithm [14] has an objective to find the varying direction of the current load. Figure 3 shows the process flow of the MPPT algorithm for the proposed system.

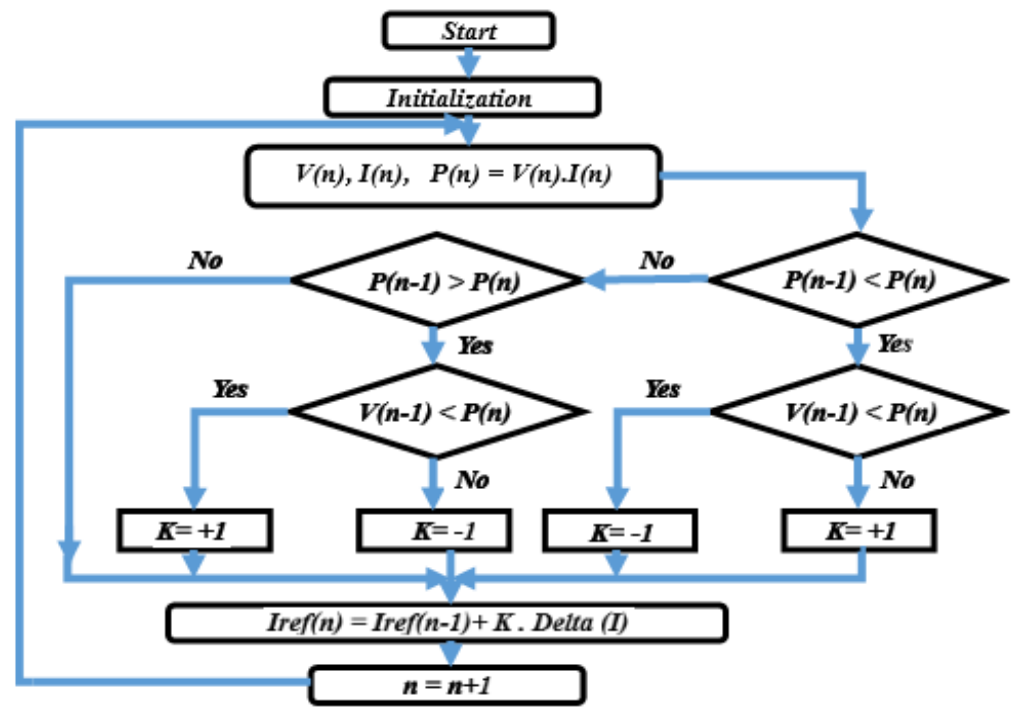

Figure 3. Flow chart of the MPPT algorithm with P\&O method [14]. 


\subsection{The Inverter}

Inverters are used in a wide range of applications, from small switched power supplies for a computer to large electric utility applications to transport bulk power [15]. They are responsible for converting DC power to AC power. This is done by switching the DC input voltage (or current) in a pre-determined sequence to generate AC voltage (or current) output. Three-phase inverters consist of one, two, or three arms of power switching devices. Each arm consists of four switching devices along with their antiparallel diodes and two neutral clamping diodes [16].

\section{WIND TURBINE}

Equation (4) gives the power generated by a wind turbine $[17,18,19,20]$.

$$
\begin{aligned}
& P_{m}=\frac{1}{2} C_{p}(\lambda, \beta) \rho \pi R^{2} V^{3} \\
& \lambda=\frac{\Omega_{t} \cdot R}{V}
\end{aligned}
$$

Where $\rho$ is the air density $\left(\mathrm{kg} / \mathrm{m}^{3}\right), \mathrm{R}$ is the blade radius $(\mathrm{m}), \mathrm{V}$ is the wind speed $(\mathrm{m} / \mathrm{s}), \mathrm{Cp}(\lambda, \beta)$ represents the power coefficient, and it can have a value between ( 0.4 and 0.5$)$. It could be expressed as equation (6) [8]:

$$
\begin{aligned}
& C_{p}=0.5872 \cdot\left(\frac{116}{\lambda_{i}}-0.4 \beta-5\right) \cdot e^{\frac{-21}{\lambda_{i}}}+0.0085 \lambda_{i} \\
& \frac{1}{\lambda_{i}}=\frac{1}{\lambda+0.08 \beta}-\frac{0.035}{1+\beta^{3}}
\end{aligned}
$$

Where; $\beta$ is the pitch angle and $(\lambda)$ is the tip speed ratio.

From $[17,18,19,20]$, the mechanical torque of the wind turbine $\mathrm{T}_{\mathrm{m}}$ is given by equation (8):

$$
T_{m}=\frac{P_{m}}{\Omega_{t}}
$$

The aerodynamic torque is given by equation (9):

$$
T_{\text {aer }}=\frac{1}{2} \cdot \rho \cdot C_{p} \cdot \pi \cdot R^{2} \cdot V^{3} \cdot \frac{1}{\Omega_{t}}
$$

Based on the above equations, we can get the turbine characteristics curve. It was shown in Figure 4. From this figure, we can see that for wind speed of $8 \mathrm{~m} / \mathrm{s}$, we can get a power about $800 \mathrm{~kW}$.

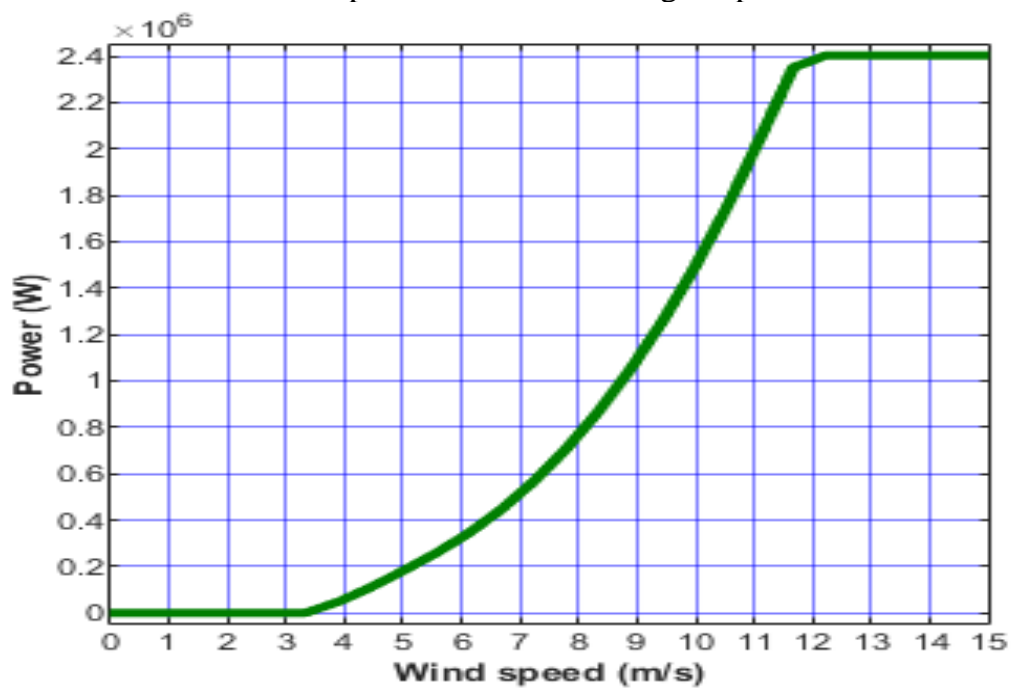

Figure 4. The turbine characteristics curve 
In this paper, the electrical generator model (DFIG) is designed using the built-in SimPowerSystem library. The rotor shaft is driven by a wind turbine, which produces mechanical torque depending on the generator and the wind speed values. The grid receives the electrical power generated by the generator through the (stator winding) depending on the operating conditions of the turbine and the generator.

\section{CONTROL STRATEGY}

As shown in [21], this system can be controlled according to the scheme shown in Figure 5. The configuration used is type DC common bus, where, the rotor is controlled by the same DFIG control structure. As well, the grid side controller is used to keep up DC-bus voltage and generate signals synchronized with the grid by the same structure of control, but with a small difference to the active power, which is the sum of active power of DFIG and PV system.

The following Figure 5 shows the outline of the proposed control.

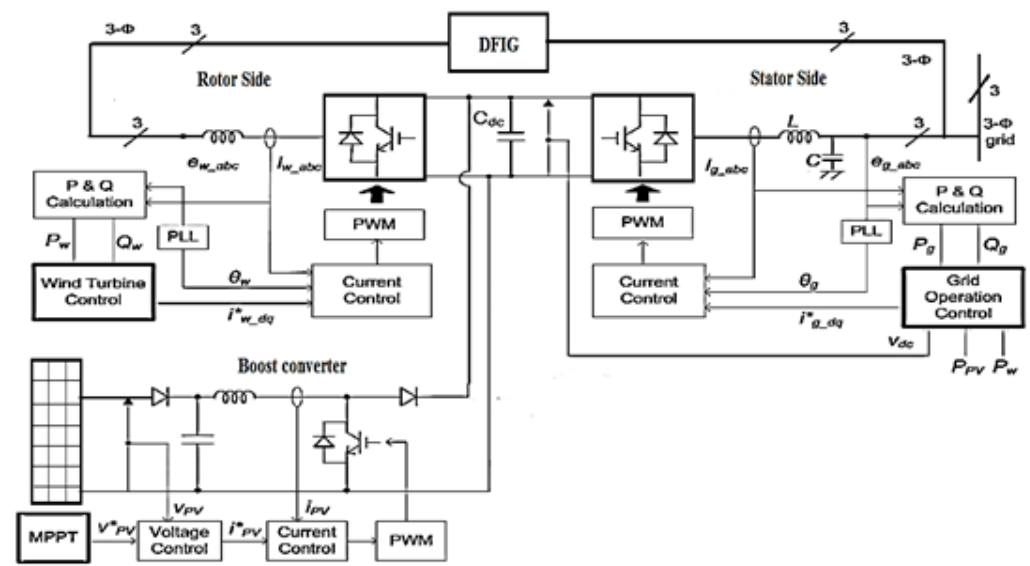

Figure 5. Configuration of the hybrid WT/PV system and its local control schematic.

For constant power, the maximum power control is overridden above rated wind speeds by the stall regulation. Figure 6 displays the rotor-side power controllers; which use PI controllers to display the new q and $d$ axis commands $i^{*}{ }_{w q}$ and $i^{*}{ }_{w d}$.
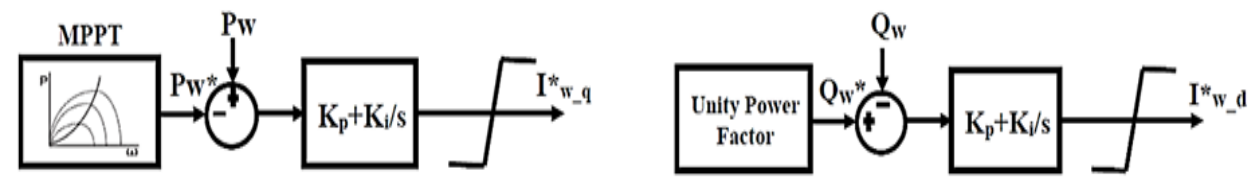

Figure 6. Power controller of the rotor side

A low-pass filter averages a total of the power obtained from the wind and solar sources, and then the filtered value is defined as the real power control [21]. The average effect of a lowpass filter can be changed by setting specific time constant. Figure 7 provides power controller for grid side.

The common DC-bus voltage is set at a constant value, so that real wind turbine and PV array power generation can be transferred into the grid. Figure 8 displays a DC voltage controller.

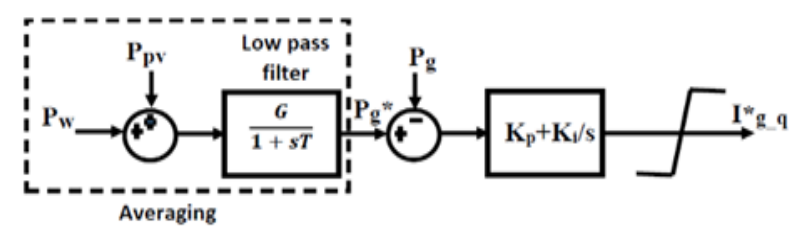

Figure 7. Power controller for grid side

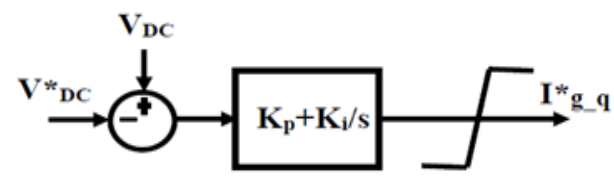

Figure 8. DC voltage controller 


\section{SIMULATION AND DISCUSSION}

The overall diagram of this system shows in Figure 9.

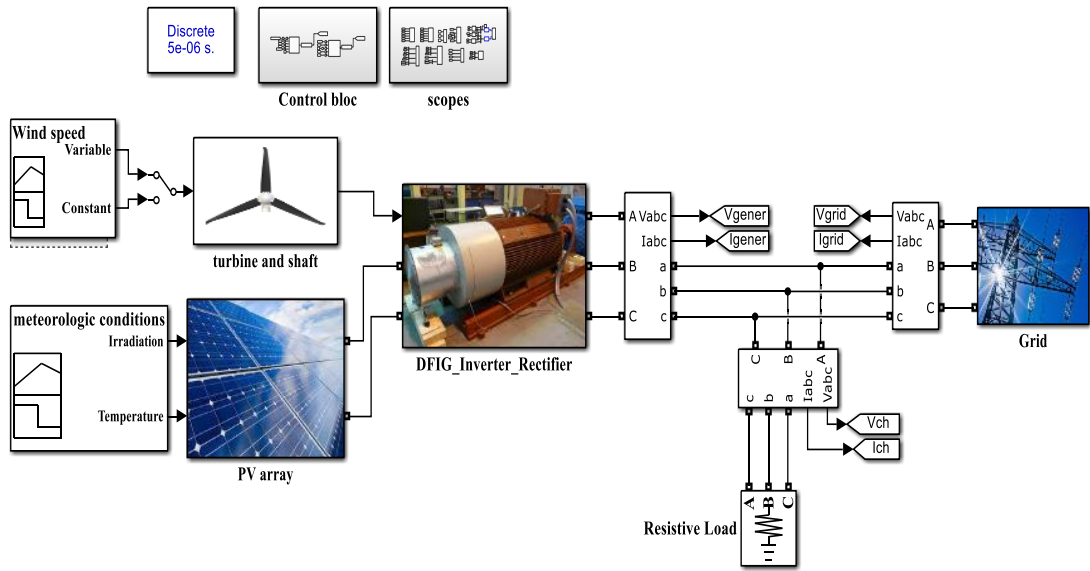

Figure 9. The overall diagram of the hybrid system

Based on the above modeling and control studies, the hybrid system operating state was simulated under specific weather conditions. Figure 9 represents the overall shape of the simulated system in the MATLAB simulink. Variable weather conditions were applied according to three modes of operation to clarify the aim of the study. These weather conditions are summarized in variable wind speed between $7 \mathrm{~m} / \mathrm{s}$ and 9.5 $\mathrm{m} / \mathrm{s}$, solar irradiance variable, which ranges between $200 \mathrm{~W} / \mathrm{m}^{2}$ and $800 \mathrm{~W} / \mathrm{m}^{2}$, and a constant temperature of $25^{\circ} \mathrm{C}$. Figure 10 shows these atmospheric variables.
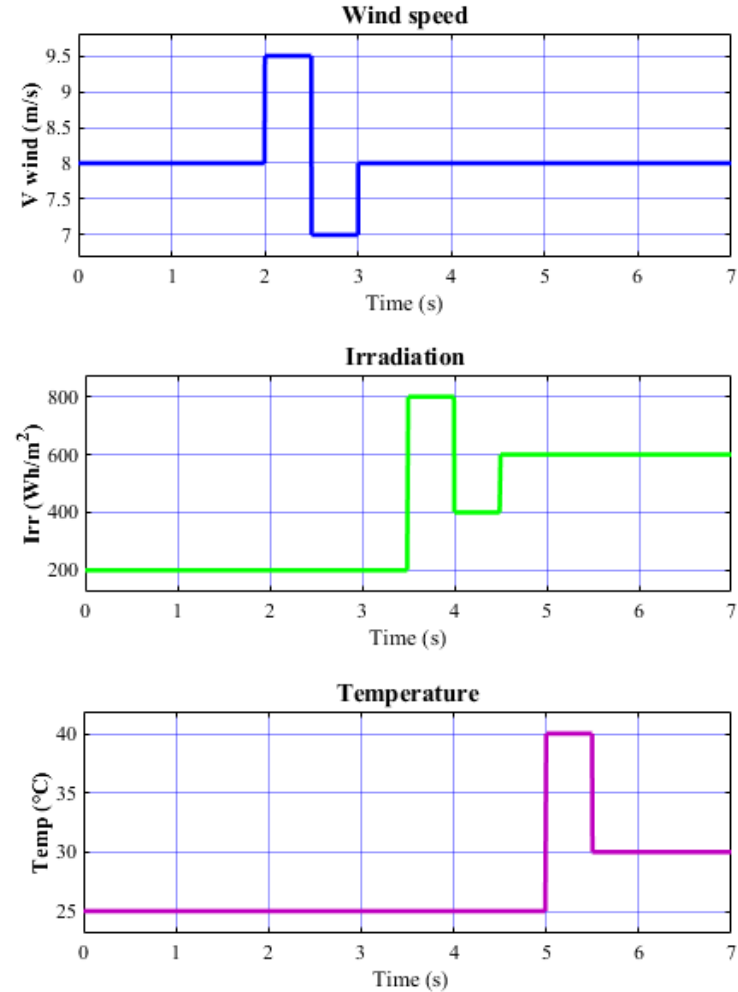

Figure 10. The proposed weather conditions

Three simulation modes were applied to show the effect of each element of weather variables on the production of power, as shown in Figure 10. One of meteorological variables is changed and others are kept constant. Where in:

Mode 1, the wind speed was changed and the temperature and radiation were kept constant.

Mode 2, the radiation value was changed and the wind speed and temperature were kept constant.

Mode 3, the temperature was changed and the wind speed and radiation values were kept constant. 
This system generates its maximum output under the aforementioned weather conditions, $1410 \mathrm{~kW}$, $1000 \mathrm{~kW}$ of wind power and $410 \mathrm{~kW}$ of solar energy. Therefore, we used solar panels containing 85 parallel sequential and 32 of the units mentioned earlier. Moreover, wind turbine include a DFIG.

We applied a variable wind speed ranging between $7 \mathrm{~m} / \mathrm{s}$ and $9.5 \mathrm{~m} / \mathrm{s}$ on the turbine blades, through which DFIG was run and its speed control through the MPPT method at about $188.4 \mathrm{rad} / \mathrm{s}$, with the production of an electromagnetic torque changes between -4000 to $-7000 \mathrm{Nm}$, as shown in Figure 11 .
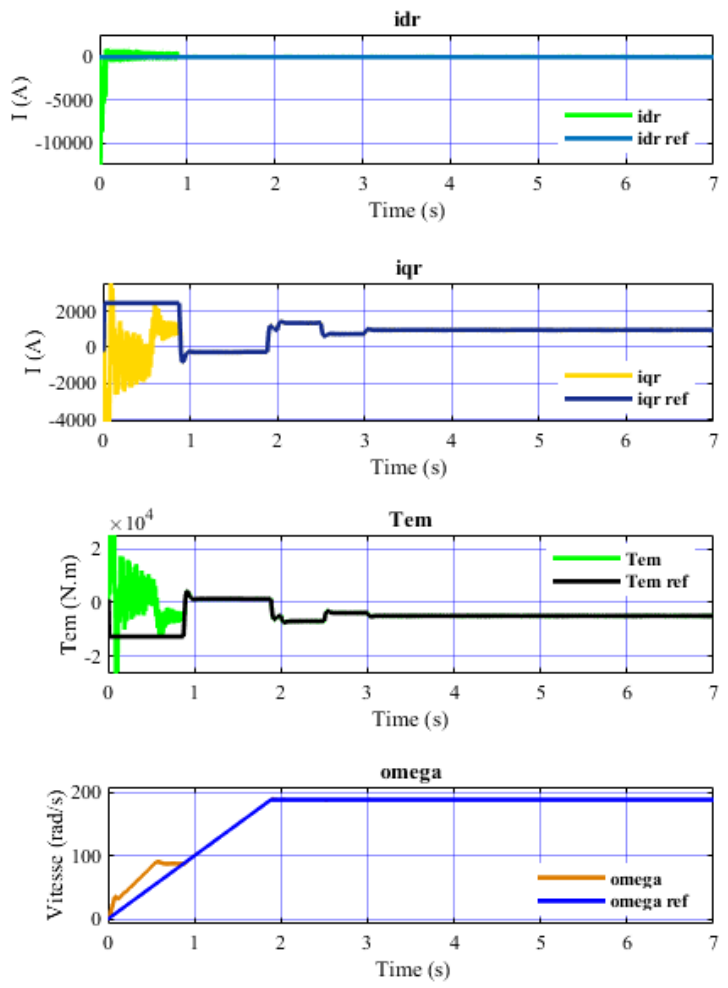

Figure 11. Results of the rotor side

The output voltage of the photovoltaic part of the system is shown in Figure 12. This voltage increases as the radiation changes. Unlooked-for changes appear in the moments 3.5 seconds and 4.5 seconds, where there is a change in the radiation value, as well as a clear change in the resulting current at the same moments mentioned above. Output boost voltage is stable around $1200 \mathrm{~V}$.
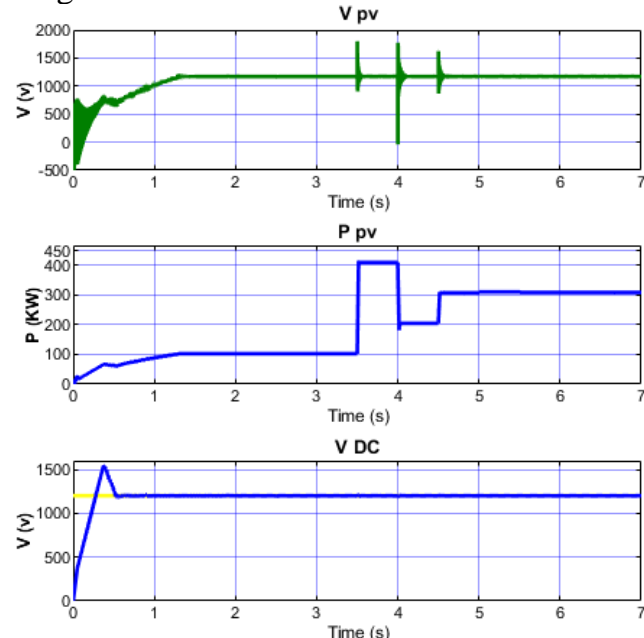

pv

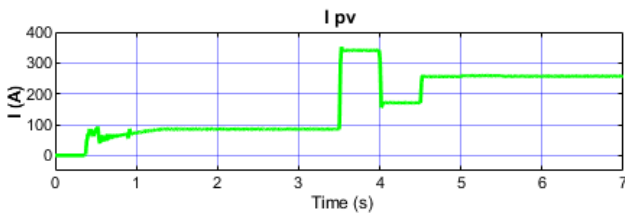

Figure 12. The PV Part result 
Figure 12, shows the resulting PV power injected into the hybrid system. This power is well followed by changes in irradiation. The change is evident in moments $3.5 \mathrm{~s}$ and $4.5 \mathrm{~s}$. The power varies between $102 \mathrm{~kW}$ and $410 \mathrm{~kW}$ depending on the evolution of the irradiation. The variation of the resulting current is also shown in the same figure.
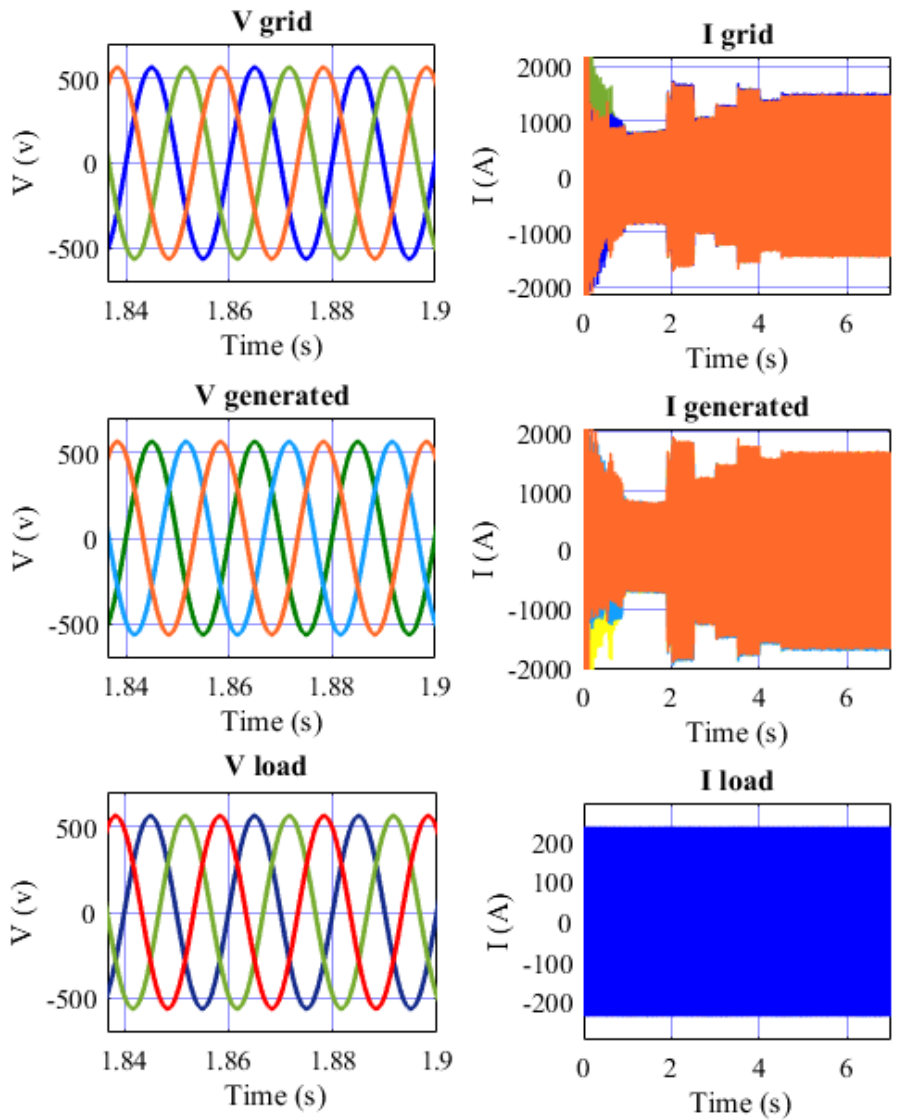

Figure 13. The aspects of voltages and currents

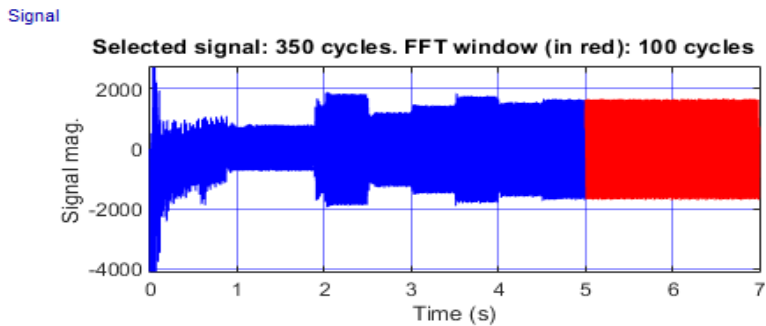

FFT analysis

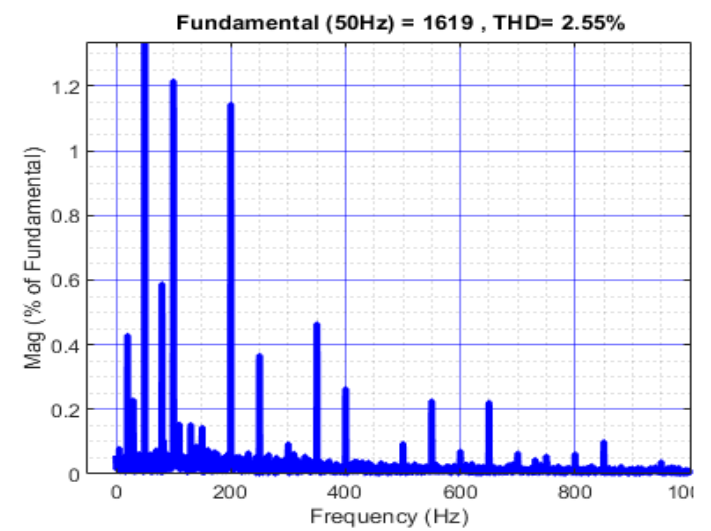

Figure 14. THD of current 
The obtained THD value was compared with the values obtained in previous work, and the results were as shown in Table 2

Table 2. A comparison of thd values for some research studies

\begin{tabular}{cccc}
\hline Paper & {$[21]$} & {$[22]$} & Current paper \\
\hline THD $(\%)$ & About 5 & 2.67 & 2.55 \\
\hline
\end{tabular}

It is noted in Figure 13 that the grid, generated, and load voltages are regular and sinusoidal. The grid and the generated current values decrease and increase according to the change in the work of the PV system, which follow the changes of the temperature and radiation.

Figure 11 depicts the quadrature and direct component currents rotor side of DFIG. These track the reference well. The direct component of the rotor currents is zero, which also gives a zero reactive power. The quadrature component of the rotor currents starts with a positive value and then changes to a negative value of $-250 \mathrm{~A}$ until the speed reaches the reference value. From 1.9s, where it becomes positive values, that change with the change in wind speed. In addition, it is finished with a fixed value of 950A.

The electromagnetic torque curve takes the opposite shape to the Iqr curve and has a clear change in the moment when the wind speed changes and finishes with a negative value $-5000 \mathrm{~N}$.m. Therefore, we can say that DFIG is a generator from time 1.9s. In this proposed system, and through Figure 14, we found that the total harmonic distortion for the generated current is around $2.55 \%$ because the wind turbine response is slower than that of the PV array; it has relatively larger DC bus ripple voltage. This is even smaller than IEEE 5121992 standard.

Figure 15 shows the components of the quadrature and direct currents grid side. These follow the reference too. The direct component takes values that change with the decrease and the increase in speed and solar radiation; this indicates the increase and decrease in the values of the currents injected to the grid. As shown in Figure 16, where we find that after the moment 1.9s the grid power becomes negative and the generated power is positive, which means that the grid receives the power from the hybrid system.

To sum up, it can be said that increasing the wind speed increases the electrical power, and decreasing it causes a decrease in the resulting power. The same thing can be said about the increase and decrease of radiation. The effect of temperature change remains weak in this system.
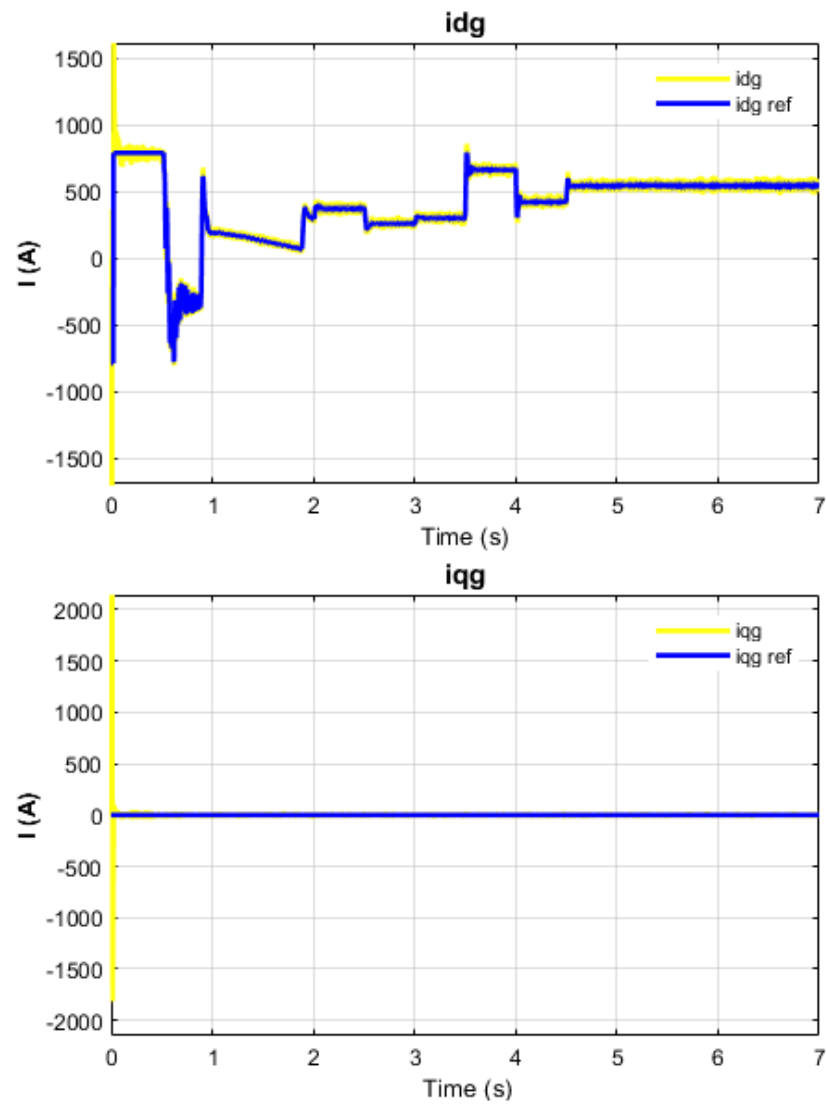

Figure 15. Results of the grid side 

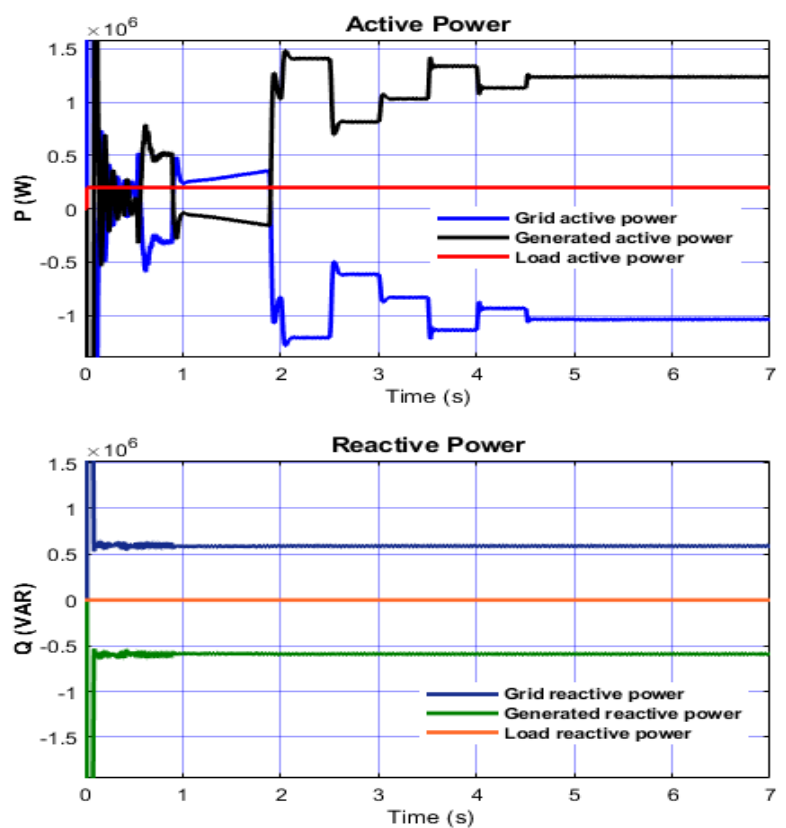

Figure 16. Active and reactive power of the hybrid system

\section{CONCLUSION}

In this study, a grid-connected wind / PV hybrid power system was simulated using MATLAB Simulink. The MPPT controller was used to extract potential electrical energy from the renewable energies used. Using three modes to control the system (by changing one of the weather variables and keeping the others constant), it was concluded that the system has the ability to produce electrical energy in the three modes. The currents injected into the grid by the hybrid system are almost sinusoidal, where a low distortion ratio was obtained (THD $=2.55 \%$ ), which is an acceptable value and better than what has been achieved in previous studies. The values of the currents increase with increasing the value of the weather variables. The reverse is correct. All simulation results obtained show that the control performance and dynamic behavior of the hybrid system connected to the grid provides good results, and they demonstrate that the proposed control system is efficient.

\section{REFERENCES}

[1] Belmili, S. Boulouma, B. Boualem, and A. M. Fayçal, "Optimized Control and Sizing of Standalone PV-wind Energy Conversion System,” Energy Procedia, vol. 107, pp. 76-84, Feb. 2017.

[2] D.-I. Stroe, A. Zaharof, and F. Iov, "Power and Energy Management with Battery Storage for a Hybrid Residential PV-Wind System - A Case Study for Denmark," Energy Procedia, vol. 155, pp. 464-477, Nov. 2018.

[3] W. Liu, N. Li, Z. Jiang, Z. Chen, S. Wang, J. Han, X. Zhang, and C. Liu, "Smart Micro-grid System with Wind/PV/Battery,” Energy Procedia, vol. 152, pp. 1212-1217, Oct. 2018.

[4] P. Kong, J. Zhao, and Y. Xing, "Series-parallel Resonant High Frequency Inverter for Standalone Hybrid PV/Wind Power System," Energy Procedia, vol. 12, pp. 1090-1097, 2011.

[5] E. Tarigan, Djuwari, and F. D. Kartikasari, "Techno-economic Simulation of a Grid-connected PV System Design as Specifically Applied to Residential in Surabaya, Indonesia," Energy Procedia, vol. 65, pp. 90-99, 2015.

[6] S. Khisa, R. Ebihara, and T. Dei, "Dynamics of a Grid Connected Hybrid Wind-Solar and Battery System: Case Study in Naivasha-Kenya," Energy Procedia, vol. 138, pp. 680-685, Oct. 2017.

[7] Rajesh K., A. D. Kulkarni, and T. Ananthapadmanabha, "Modeling and Simulation of Solar PV and DFIG Based Wind Hybrid System," Procedia Technology, vol. 21, pp. 667-675, 2015.

[8] Agrawal H., "Control of Grid Interfacing Photovoltaic Generation System", International Journal of Emerging Trends in Science and Technology, IJETST, Vol. 01,no. 07, pp. 1222-1226. 2014.

[9] Ravi K., Sakthigokulrajan C., Shilaja C., "Modeling of photovoltaic energy conversion system with integration to substation", Global journal of pure and applied mathematics, vol. 10, pp. 451-464, 2014.

[10] Benkhelil E., Gherbi A., "Modeling and simulation of grid-connected photovoltaic generation system", Revue des energies renouvelables SIENR, pp. 295-306. 2012.

[11] Samrat N H., Ahmad N., Choudhury I A., Taha Z., "Technical Study of a Standalone Photovoltaic-Wind Energy Based Hybrid Power Supply Systems for Island Electrification in Malaysia”, PLOS ONE, vol. 10, no. 6, p. e0130678, 2015. 
[12] Haque M., Sharma S., Nagal D., "Proposed Inverter Topology and Control Circuit for the Proposed Grid Connected Photovoltaic System: Description and Design Specification", International Conference on Electrical, Electronics and Optimization Techniques (ICEEOT), pp 549-554, 2016.

[13] T. Ibrahim, "Maximum Power Point Tracking for Photovoltaic Systems in rapidly changing environmental conditions", The 8 Jordanian International Electrical and Electronics Engineering Conference (JIEEEC). 2013.

[14] S. Ki Kim, J. Hong Jeon, C. Hee Cho., "Dynamic Modeling and Control of a Grid-Connected Hybrid Generation System with Versatile Power Transfer", IEEE transactions on industrial electronics, vol. 55, no. 4, pp. 1677-1688, 2008.

[15] Bouhafs A., Lokmane B., Mohamed D., "Grid connected photovoltaic system for 800W”, Energy Procedia, vol. 74, pp. 414-422, 2015.

[16] A.Y.Mohammed, F. L.Mohammed, M.Y.Ibrahim, "Grid Connected Photovoltaic System", International Conference on Communication, Control, Computing and Electronics Engineering (ICCCCEE), 2017.

[17] Bensaadi H., Harbouche Y, Abdessmed R., "Direct Torque Control (DTC-SVM) of PMSG Based in Wind Energy Conversion System”, U.P.B. Sci. Bull., Series C, Vol. 81, no. 2, pp. 227-240, 2019.

[18] El Amine B. B. M., Ahmed A., Houari M. B., Mouloud D., "Modeling, simulation and control of a doubly-fed induction generator for wind energy conversion systems", International Journal of Power Electronics and Drive Systems (IJPEDS), vol. 11, no. 3, pp. 1197-1210, 2020.

[19] E.Natsheh, A.Albarbar, J.Yazdani, "Modeling and control for smart grid integration of solar/wind energy conversion system", 2nd IEEE PES International Conference on Innovative Smart Grid Technologies (ISGT Europe), pp.1-8, 2011.

[20] N.S. Jayalakshmi, D.N. Gaonkar, R.P. Karthik, P. Prasanna, "Intermittent power smoothing control for grid connected hybrid wind/PV system using battery-EDLC storage devices", Archives of Electrical Engineering (AEE), Vol. 69, no. 2, pp.433-453, 2020.

[21] Chen, Y.-M. et al., "Multi-Input Inverter for Grid-Connected Hybrid PV/Wind Power System", IEEE Transactions on Power Electronics, Vol. 22, no. 3, pp.1070-1077, 2007.

[22] Partha Sarothi Sikder, Nitai Pal, "Modeling of an intelligent battery controller for standalone solar-wind hybrid distributed generation system", Journal of King Saud University - Engineering Sciences, Vol 32, no 6, pp 368-377, 2020 .

\section{BIOGRAPHY OF AUTHORS}

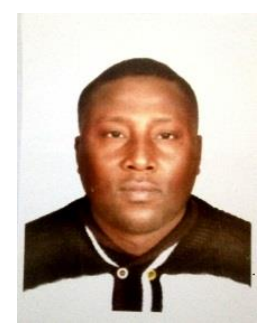

Abdelhamid Slama was born on August 15, 1983. He received the magister degree in Electrical Engineering from ENP-MA Oran, Algeria and Bachelor of Technology from ENSET Oran in 2016 and 2006. He is currently a PHD student in Electrical Engineering Department of ENP-MA Oran, and a researcher in the SCAMRE Laboratory. His areas of intrest include Hybrid renewable energy systems and Power electronics.

Messaoud Hamouda is a Professor in the Faculty of Science and Technology, Ahmed Draia University. He is a Director of the Development Laboratory Sustainable and Computing (LDDI). His areas of interest include electrical machines, wind energy conversion, solar energy conversion and power systems. He has authored several scientific papers and international communications.

Mounir Khiat is a Professor in Electrical Engineering Department of ENP-MA Oran. He is a researcher in the SCAMRE Laboratory. His areas of interest include electrical machines, electrical network and power systems. He has authored several scientific papers and international communications. 